\title{
Claudio Pierantoni
}

Profesor de la Facultad de Teología

Pontificia Universidad Católica de Chile

\section{El milenio en la patrística: ¿alternativa entre interpretación literal e interpretación alegórica?}

Los textos bíblicos son a menudo exégesis, reinterpretación de textos o temas bíblicos anteriores. En este sentido, no es difícil notar cómo el texto de Apoc 20 es una exégesis de textos mesiánicos y una reinterpretación de la edad del oro profetizada en Isaías. Ahora bien, como ya ha sido evidenciado en un artículo de la revista Augustinianum de 1978 (1), la presentación del milenio en los primeros autores cristianos -todos de ambiente asiático (2): Cerinto, Papía, Justino, Ireneo- se diferencia netamente de la presentación del Apocalipsis joánica. Leamos por ejemplo algunas líneas. De los primeros dos, Cerinto y Papía, solo poseemos citas indirectas:

Eusebio de Cesarea, Historia Eclesiástica III, 28: "Esta es la doctrina que enseñaba [Cerinto]: el reino de Cristo será terrenal. Y como amaba el cuerpo y era del todo carnal, imaginaba que iba a encontrar aquellas satisfacciones a las que anhelaba, las del vientre y del bajo vientre, es decir del comer, del beber, del matrimonio: en medio de fiestas, sacrificios e inmolaciones de víctimas sagradas, mediante lo cual intentó hacer más aceptables tales tesis".

Esta noticia, tomada de una obra de Dionisio de Alejandría, es sustancialmente confirmada por una serie de testimonios: Jerónimo, Agustín, Teodoreto, Isidoro de Sevilla.

Del milenarismo de Papía de Hierápolis también tenemos testimonios en Eusebio, Jerónimo, Genadio, Máximo el Confesor, pero el testimonio más interesante es sin duda el de Ireneo, sobre todo porque este lo relaciona con una tradición más amplia, que identifica como "los presbíteros", y conecta directamente con el apostol Juan:

Ireneo, Adversus Haereses III, 33, 3: “Así, los presbíteros, que vieron a Juan discípulo del Señor, recuerdan haber oído de él las enseñanzas y las palabras del Señor a propósito de aquellos tiempos: "Llegarán días, en los cuales nacerán viñas

(1) Mazzucco - Pietrella, Il rapporto tra la concezione del millennio dei primi autori cristiani e l'Apocalisse di Giovanni.

(2) Con los términos "Asia" y "asiático", no se entiende aquí genéricamente el "continente asiático", sino específicamente la provincia romana de "Asia”, o Asia proconsular, que corresponde grosso modo a la región costera occidental del Asia Menor. 
con diez mil sarmientos y en cada sarmiento diez mil brazos y en cada brazo diez mil ramitos y en cada ramito diez mil granos y cada grano exprimido producirá veinticinco medidas de vino. Y cuando uno de los santos recogerá un grano, otro gritará: 'Yo soy mejor, por medio mío bendice al Señor. De manera parecida, también un grano de trigo producirá diez mil espigas y cada espiga tendrá diez mil granos y cada grano rendirá cinco medidas dobles de flor de harina pura y todos los demás frutos y simientes y hierbas según la analogía que se sigue, y todos los animales nutriéndose de los productos recibidos de la tierra se tornarán pacíficos y vivirán en armonía, en todo sometidos al hombre".

Justino, por su parte, es el primer escritor cristiano cuya doctrina milenarista leemos en una obra que nos ha llegado directamente. Se trata del "Diálogo con Trifón”, un judío culto: aunque Justino no es propiamente asiático de nacimiento, el diálogo se desarrolla en Efeso, la metrópolis más importante del Asia proconsular, y una ciudad donde la tradición judía era muy fuerte e influenciaba profundamente la comunidad cristiana. El judío Trifón muestra un momento de duda en creer en la sinceridad de las palabras de Justino sobre la profesión de milenarismo por parte de los cristianos, y Justino explica entonces :

Diálogo 80, 2 : "No soy tan mezquino, o Trifón, como para hablar distinto a como pienso. (...) Por otro lado, te he dicho que muchos, incluso entre los cristianos de mente pura y religiosa, no aceptan esta doctrina (...). Yo, junto con los cristianos de total ortodoxia (ojrqognwvmones kata; pavnta Cr),isabemos íque habrá resurrección de la carne y los mil años en Jerusalén reedificada, renovada y ampliada, como lo dicen los profetas Ezequiel, Isaías y los demás".

Siguen las famosas citas de Ezequiel 37, 12-14 e Isaías 65, 17-25.

Como se ve, por un lado Justino admite que no todos los "buenos" cristianos son milenaristas, sin embargo no teme en afirmar que el milenarismo es parte integrante de una ortodoxia verdaderamente completa. El otro aspecto interesante en el relato de Justino se halla en el cap. 83, 4, donde el autor conecta la doctrina con el texto del Apocalipsis, y coloca explícitamente los mil años en Jerusalén, allí donde el texto biblico hacía discretamente referencia a la "ciudad amada", y se servía en cambio del nombre de Jerusalén para describir la consumación total del tiempo, la Jerusalén propiamente celestial.

Ireneo se nos presenta, dentro del ambiente asiático, como el punto de llegada, el punto culminante en el cual la idea del milenarismo es integrada dentro de una visión teológica coherente. Leamos el pasaje que nos parece más importante:

Adversus Haereses V, 32, 1 : "El pensamiento de algunos es inducido a error por discursos de herejes, a punto tal que ignoran los designios de la salvación de Dios y el misterio de la resurrección de los justos y del reino que es el principio de la incorrupción. Este reino es el medio por el cual los que habrán sido estimados dignos, poco a poco se acostumbrarán a acoger a Dios. En consecuencia, a propósito de ellos hay que decir que los justos, resucitando los primeros en esta creación que se renueva por la manifestación del Señor, recibirán la herencia prometida por Dios a los padres y reinarán. Sucesivamente habrá el juicio. Tal como es justo, ellos recojen los frutos de su paciencia justamente en la creación en la cual sufrieron o fueron atormentados y puestos a prueba en todas las maneras en su paciencia; reciben la vida justamente en aquella creación en la que fueron muertos por motivo del 
amor de Dios, y reinan justamente en aquella creación en la que soportaron la esclavitud. Dios efectivamente es rico en todo y todo le pertenece. También la Creación, por lo tanto, restaurada en su condición original, debe ser puesta a servicio de los justos sin ningún obstáculo. El Apóstol Pablo lo declaró en la carta a los Romanos: La Creación fue sometida a la caducidad, no por su voluntad, sino por la voluntad del que la sometió, porque también la Creación será liberada de la esclavitud de la corrupción, para entrar en la libertad de la gloria de los hijos de Dios (Rom 8, 19-21). Así también la promesa que Dios hizo a Abraham dura de manera irrevocable. Dios dijo efectivamente: Mira hacia arriba con tus ojos, y mira desde donde estás ahora hasta el norte, el sur, el oriente y el poniente y el mar: porque toda la tierra que ahora ves, te la daré a ti y a tu descendencia para siempre (Gen 13, 14-15)".

En el contexto de la polémica antignóstica, Ireneo tiene la ocasión para valorizar al máximo el tema del milenio, enganchándolo con uno de los temas básicos de la revelación cristiana: la salus carnis. La encarnación del Verbo, en su estrecha relación con la necesidad de la Redención, impulsa a una inevitable consecuencia: toda la creación, incluyendo todos sus aspectos materiales, es redimida e insertada en Cristo. Por lo tanto incluso divinizada, lo que Ireneo llama el capere Deum. De allí viene la relación coherente entre las promesas veterotestamentarias, a partir de las promesas hechas a Abraham hasta las profecías más recientes por un lado, y la afirmación tan sublime y universal de Rom 8, 21 por el otro. (De las profecías veterotestamentarias, Ireneo reúne un buen número: Is 6, 11; Dan 7, 27; 12, 13; Jer 38,10 ; Is 31, 9-32; 54, 11-14; 65, 18-22).

A partir de eso, se plantea una tajante polémica contra la interpretación alegórica y espiritualizante de dichas promesas, propia de los gnósticos, y que arriesgaba poner en duda justamente, con la "resurrección de los justos", el núcleo mismo de la revelación cristiana. Para prevenir el ser acusado de una interpretación judaizante del Antiguo Testamento, Ireneo reúne un dossier neotestamentario en apoyo de su tesis fundamental, que incluye palabras indiscutiblemente atribuidas al mismo Jesús: en particular, la beatitud de los mites, que heredarán la tierra, el versículo de Mateo 26, 27 sobre Jesús que va a beber de nuevo el fruto de la vid en el reino de su Padre, y la afirmación de Mateo 19, 29 que dice: "Cualquiera que abandone campos o casas o padres o hermanos o hijos por causa mía, recibirá el céntuplo en este tiempo, y en el futuro la vida eterna".

Sobre todo estas últimas palabras parecen confirmar de la manera más evidente que los tiempos propiamente escatológicos (la vida eterna) serán precedidos por una era de felicidad terrenal (en este tiempo). Así se expresa por lo tanto Ireneo para contrastar la interpretación alegórica, en una de las síntesis más vigorosas de su teología:

Adversus Haereses V, 35, 2: "Y ninguno de estos detalles se puede entender en sentido alegórico, sino que son todos firmes, verdaderos y sustanciales (omnia firma et vera et sustantiam habentia) hechos por Dios para beneficio de los justos. Tal como Dios resucita al hombre verdaderamente, así también el hombre resucitará de los muertos verdaderamente y no en sentido alegórico, como lo hemos demostrado con argumentos tan concluyentes; y tal como resucitará verdaderamente, así se ejercitará verdaderamente de antemano en la incorrupción y crecerá y cobrará fuerza en 
los tiempos del reino para llegar a ser capaz de la gloria del Padre (ut fiat capax gloriae Patris): después, con la renovación de todas las cosas, habitará verdaderamente en la ciudad de Dios". Sigue la cita de Ap 20, 21 sobre la renovación de todas las cosas, y sigue el autor:

"Tal como los hombres son verdaderos, también ha de ser verdadera su traslación (translatio), no ciertamente un pasar al no ser, sino un progreso en el ser (non excedere in ea quae non sunt, sed in his quae sunt proficere). Porque no es aniquila-

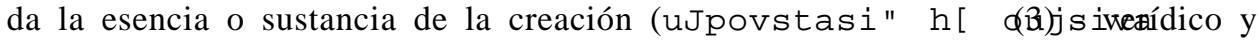
estable es El que la ha constituida, sino que pasa la figura (sch 'mł de este mundo, es decir, de la realidad en la que se realizó la transgresión, ya que en ella el hombre se hizo viejo. Y por este motivo fue hecha aquella figura momentánea, porque Dios todo lo conoce de antemano. Pasada esta figura, renovado el hombre y crecido en orden a la incorrupción, como para no poder envejecer de nuevo, habrá un cielo nuevo y una tierra nueva: en estas cosas nuevas el hombre permanecerá siempre nuevo en coloquio con Dios".

En la visión pedagógica de Ireneo, la consumación del mundo no puede ser concebida como el abandono de una dimensión inferior, terrenal, hacia una dimensión superior, celestial, en un movimiento con dirección esencialmente vertical, sino que debe ser pensada como un crecimiento gradual de toda la realidad creada, encabezada naturalmente por el hombre, en un movimento ascensional oblicuo, donde -con la excepción del pecado- nada es abandonado, sino todo es recuperado, o recapitulado. Por este motivo estas expresiones bíblicas no pueden ser referidas a "realidades que están sobre el cielo", como pretenden los gnósticos, sino que deben ser entendidas literalmente. A este punto, es necesario introducir una pequeña precisión de naturaleza filosófica. Ha sido afirmado innumerables veces que la exégesis alegórica o espiritual, tanto gnóstica como católica, que tiende a interpretar tan numerosos pasajes de la Biblia a veces destruyendo, a veces sobreponiéndose a su contenido literal para acentuar su correspondencia con realidades celestiales o "supracelestiales", sería característica específica de un planteamiento platónico, caracterizado esencialmente por una bipartición vertical de la realidad. Sin negar en absoluto que haya una verdad en esto, es indispensable en mi opinión agregar una precisión: la bipartición vertical de la realidad es característica esencial de la fase intermedia de la reflexión platónica, la que corresponde en práctica al Simposio, al Fedón y al Fedro: ahora bien, es indispensable no considerar estos diálogos como exhaustivos del pensamiento de Platón, específicamente en su relación con la teología cristiana. Es fundamental a este propósito tener en mente la importancia que tuvieron los sucesivos desarrollos de la filosofía de Platón, atestiguados por los diálogos de la vejez, en especial, el Sofista, el Parménides y el Timeo. En este último especialmente se encuentran expresados en forma más sencilla y fácilmente entendible por un público menos especializado, algunos aspectos esenciales de la reflexión platónica en orden a la relación entre el plano Ideal y el plano Sensible. Para dar un ejemplo muy concreto, lo que antes hemos leído en Ireneo sobre el absurdo de pensar la escatología como aniquilación de lo creado, se basa en el

(3) Este pasaje lo poseemos conservado en un fragmento original griego. 
supuesto de que Dios, su Creador, es verídico y estable (ajlhqhv" kai; b£:vbaio" ahora bien, la afirmación tiene su antecedente directo en una importante página del Timeo, donde Platón propone una nueva demostración de la inmortalidad del alma, mucho más simple, pero quizás más profunda todavía de las que discute en el Fedón: el Alma, que a estas alturas de la reflexión platónica es concebida como Alma de Mundo, junto con el Mundo al que ella misma anima, debe necesariamente ser inmortal, por el simple hecho de que a Dios, que es el principio de nuestra racionalidad, solo lo podemos concebir como bueno, y un Dios bueno solo puede producir, o engendrar un mundo bueno, y algo bueno, una vez producido, no tiene ningún motivo para ser destruido, por lo tanto es lógico que Dios mismo le done la inmortalidad (4). Resulta evidente por lo tanto cómo Ireneo capte con maravillosa síntesis la teología bíblica del lento progreso del hombre hacia Dios, que a su vez incluye y completa los resultados más avanzados y fecundos de la filosofía griega en su prodigiosa reflexión sobre la racionalidad e intrínseca bondad del universo.

El otro aspecto del milenarismo de Ireneo que vale la pena mencionar se refiere a la relación, que se manifiesta por primera vez en este autor, entre el milenio del Apocalipsis y los siete días de la Creación. Ya que según el Salmo 89, 2 mil años son como un solo día delante del Señor, se legitima la interpretación de los siete días del Génesis como correspondientes a siete mil años previstos como tiempo de toda la historia. Y en esta interpretación resulta también perfecta la correspondencia entre el séptimo día que el Génesis consagra al descanso de Dios, y el reino de los justos en que cesará todo problema, toda lucha por la sobrevivencia y por lo tanto todo trabajo del hombre.

Finalmente, cabe subrayar que Ireneo no propone una estrecha relación entre la doctrina milenarista y el texto del Apocalipsis: solo cita dos veces el texto joánico (Apoc 19, 20 y 20,6) a propósito del milenio propiamente tal, mientras que las referencias más amplias están dedicadas a la descripción del juicio final y del descenso de la Jerusalén celestial del cap. 21.

Este dato, en armonía con toda la documentación asiática que hemos mencionado sobre el milenio, nos conduce a una reflexión fundamental: el milenarismo asiático se nos presenta con características y detalles que van mucho más allá del texto joánico, y es por lo tanto evidente que no hay que buscar en el Apocalipsis la fuente primaria de tales doctrinas, sino que, casi al revés, una reacción a tales doctrinas, para corrigir precisamente sus aspectos más groseros y "materialistas". Se ha hablado, en tal sentido, incluso de un "antimilenarismo" del Apocalipsis. Sin embargo, hay que ser muy cautos al propósito, porque esto implicaría una indirecta infravaloración de la relevancia teológica de las doctrinas milenaristas, condenadas implícitamente por este supuesto "pecado original" del materialismo. Evidentemente, en cambio, el autor del texto ha querido, aun corrigiéndolos en parte, insertar ciertos datos tradicionales judeo-cristianos sobre la escatología. Datos quizás aparentemente ingenuos, pero en realidad considerados por él serios y profundos.

Pasemos ahora a la reacción alejandrina. Como es sabido, una decidida reacción contra las doctrinas milenaristas vino de la escuela exegética de Alejandría de Egipto, en algunos de sus máximos exponentes: Clemente, Orígenes, Dionisio, Dídimo. Del 
testimonio de los alejandrinos y del tono bastante violento de su polémica contra el milenarismo, se deduce fácilmente que tales doctrinas, que hemos visto en su ambiente más típico en el Asia proconsular, eran sin embargo muy difundidas también en Egipto, sobre todo a nivel popular. En una obra de Dionisio de Alejandría, "En torno a las promesas", citada por Eusebio, leemos por ejemplo que él mismo, en calidad de obispo, había sostenido una discusión, en un pueblo cerca de la capital, con el jefe de la comunidad local, que era totalmente milenarista: la discusión había durado tres días enteros seguidos, y al final el jefe de la comunidad se había declarado convencido. "De los otros fieles - continúa el texto- mientras algunos (oi J mese uniformaron al acuerdo logrado...". Aquí bruscamente termina la cita de Eusebio, que a pesar de su censura nos deja fácilmente suponer el resto de la frase, algo como: "otros en cambio ( oi J ) dse quedaron con sus ideas (es decir milenaristas)". Es obvio suponer que sobre todo las personas más humildes, cuyo horizonte de vida no daba mucho espacio a esperanzas de parte del orden político y social, no encontraran fácilmente un motivo para renunciar a la esperanza milenarista.

Veamos ahora las líneas generales del razonamiento exegético de Orígenes a este propósito. Como sabemos, Orígenes está convencido de que toda frase de la Biblia tiene un sentido a nivel espiritual o alegórico, mientras que no toda frase puede tener necesariamente un significado literal: hay pasajes que según él no tienen absolutamente ningún sentido si son tomados literalmente. Pero esto, en un sistema que pretende obedecer a una lógica rigurosa, no se puede dar por obvio, sino que hay que demostrarlo: hay que dar una demostración que nos hallamos frente a lo que él llama "defectus litterae", es decir a un sentido literal absurdo o incomprensible. Esto es precisamente lo que nos obliga a tomar en consideración exclusivamente el sentido espiritual o alegórico. Ahora bien el milenio, sobre todo en el Apocalipsis, aunque presente dificultades de interpretación, no se presta fácilmente a ser considerado absurdo o incomprensible. Algunos pasajes bíblicos, por ejemplo Prov 9, 1, que muestra la Sabiduría personificada preparando un banquete con vino y pan para sus seguidores, permiten a Origenes una interpretación alegórica generalizada de todas las profecías que hablan de fertilidad de la tierra, abundancia de frutos, etcétera. Pero esto, nótese bien, no es suficiente para excluir la interpretación literal de la profecía del milenio, ya que la interpretación alegórica de tales imágenes, aun aceptada, puede fácilmente ser referida a la espera escatológica definitiva, y no necesariamente al milenio. Así por ejemplo, la conversación de Jesús con los saduceos en Mateo 23, 30 se concluye con las famosas palabras: "Vosotros os engañáis, no conociendo las Escrituras ni la potencia de Dios. En la resurrección no se casarán, sino que serán como ángeles del cielo”. El nexo con la interpretación alegórica es individuado aquí por Orígenes en la imposibilidad de encontrar en las Escrituras literalmente esta enseñanza que Jesús propone: por lo tanto el Alejandrino deduce que la "ignorancia" de las escrituras no puede referirse a la "letra" de ellas, sino debe ser una ignorancia de su sentido alegórico, espiritual. En sí una deducción brillante, pero en lo que se refiere específicamente al milenio, no definitiva. De hecho, ya Ireneo había fácilmente referido esta afirmación de Jesús sobre el matrimonio a la resurrección universal final, sin que esto le impidiera referir otras profecías de caracter material a la primera resurrección. Es importante notar, por lo tanto, que el método y el razonamiento exegético en sí no son suficientes, en Orígenes, 
para descartar el milenio, y el Alejandrino se ve por lo tanto obligado aquí a una forma de petición de principio, que deriva directamente de su manera de considerar el mundo material. Sin embargo, es muy interesante observar que a la vez Orígenes, aun distanciándose tanto de Ireneo en este aspecto material del reino escatológico intermedio, no descarta en sí la idea de un tiempo intermedio, aunque sea de tipo racional-espiritual. Leemos por ejemplo en el De Principiis:

II, 11, 6 : "Pienso que los bienaventurados, alejándose de esta vida, permanecerán en un lugar de la tierra que la Sagrada Escritura llama paraíso, como en un lugar de instrucción y por decirlo así, una escuela de las almas, donde recibirán enseñanzas sobre todo lo que habían visto en la tierra. Cuando estábamos en la tierra, hemos visto animales y plantas y hemos notado sus diferencias y diversidad entre los hombres; pero viendo tales cosas, no hemos comprendido la razón de ellas, y la diversidad de las cosas que veíamos nos ha sugerido solamente investigar y buscar por qué motivo todos estos seres hayan sido creados diferentes y estén ordenados de manera diferente. Habiendo concebido en la tierra el amor y el estudio por tal conocimiento, después de la muerte nos será concedido realizarla plenamente".

La diferencia de planteamiento con respecto a Ireneo es clara: las almas (no los hombres) no estarán viviendo en nuestro mundo material, pacificado y "potenciado”. Sin embargo, sí estarán viviendo -nótese bien- en un lugar de la tierra, es decir, todavía dentro de la Creación, de alguna manera también material: es importante tener presente que para Orígenes, como para los estoicos, existen diferentes tipos o grados de materia, y el hecho que el alma se separe del cuerpo con la muerte, no significa que se quede en un estado completamente inmaterial: sigue contando con un vehiculum de materia, más fina y más sutil, que le permite moverse y seguir su ascenso a través de regiones más elevadas y privilegiadas, pero que siempre son parte de la Creación material. A este propósito, subrayemos que "paraíso" se entiende aquí en sentido distinto al nuestro, y probablemente hay que identificarlo con la "tierra verdadera", que Orígenes coloca sobre el cielo de las estrellas fijas, y que en una homilía sobre el Salmo 36 describe como "tierra buena, tierra santa, tierra abundante, tierra de los vivientes, tierra de leche y miel". Es superior a la tierra de aquí abajo, que Orígenes llama "árida", en armonía con el relato de la Creación; es un lugar de la tierra que a su vez tiene su cielo, que es el cielo propiamente tal: es evidente la armonización de los datos bíblicos con la cosmología de la República platónica. Es importante notar, en base a esto, que la tantas veces criticada infravaloración de la materia en el ambiente platonizante del cristianismo alejandrino culto, necesita también una aclaración: si hay un lugar de la tierra donde se instruyen las almas, que pueden ascender a través de cielos materiales contando con su vehículo material, aunque de materia más sutil -y notemos también que objeto de la instrucción son en primer lugar las relaciones racionales entre los seres sensibles (recordemos la citada página del Timeo) - eso significa que no es la materia en sí que pueda ser concebida negativamente. El mundo material como lo conocemos nosotros, con sus problemas y sus males, es en definitiva siempre un producto del pecado humano, no de una esencia en sí negativa: la caída del hombre hay que concebirla no como una caída desde lo inmaterial a lo material (como a veces superficialmente se interpreta), sino desde lo material de grado más elevado a lo material de grado inferior. Aun en Orígenes por lo tanto el famoso "dualismo" es siempre, en su esencia -así 
como en el Nuevo Testamento- una dicotomía u oposición ética, y nunca metafísica. El ascenso ético del hombre mantiene entonces intacta la importancia de la dimensión de la gradualidad y de la lenta pedagogía divina con respecto a la Creación, que hemos encontrado en Ireneo, a pesar de la distinta atmósfera cultural.

La idea que el núcleo más profundo de la doctrina milenarista no es de por sí incompatible con el cristianismo de ambiente platonizante, es confirmada además por la interpretación de un autor un poco menos conocido, pero que a este propósito considero sumamente interesante: Metodio de Olimpo. Un poco posterior a Orígenes, Metodio escribió, tras las huellas de Platón, un Simposio: en el noveno discurso de esta obra un tanto singular, el autor propone su interesante interpretación del milenio. Empecemos notando la singularidad que aquí justamente la interpretación alegórica, y no la literal, está puesta al servicio del planteamiento milenarista: se trata de Levítico 23, 39-43, la fiesta de las tiendas: la verdadera interpretación de este precepto, al igual que la de todos los preceptos del Antiguo Testamento, es para Metodio exclusivamente alegórica. Las tiendas significan los cuerpos resucitados. La fiesta se celebrará por tanto en el séptimo milenio, en la creación nueva y sin dolor, cuando los frutos de la tierra habrán terminado de crecer, cuando los hombres habrán terminado de nacer, cuando Dios descansará: en fin, cuando el cosmos habrá llegado a su télos (fin). Escuchemos directamente a Metodio:

Simposio IX, 5: "Habiéndome alejado del Egipto de esta vida, llego primero a la resurrección, la verdadera fiesta de las tiendas. Allí habiendo plantado la mía, adornada de los frutos de la virtud para el primer día de la resurrección, para el juicio, celebro con Cristo el milenio del reposo, los llamados siete días, el verdadero sábado. Después, de nuevo, siguiendo a Aquel que penetró los cielos (Heb 4, 14), Jesús, llego a los cielos, como también aquellos, después del reposo de la fiesta de las tiendas, a la tierra prometida, sin quedarme en las tiendas: es decir, mi tienda no permanecerá igual, sino que después de los mil años se cambiará del aspecto ( sch 'młhumano y de la corrupción en belleza y grandeza angélicas”.

En esta concepción conviven pacíficamente la interpretación alegórica de los frutos, ríos, árboles de las profecías mesiánicas, con el tiempo escatológico intermedio del texto del Apocalipsis. Es clara la diferencia con respecto al milenarismo material asiático, pero también es clara la distancia con respecto a Orígenes: Metodio, autor profundamente helenizado, convencido partidario de la interpretación alegórica, aquí no menos de Ireneo intuye la importancia de una posible conexión entre doctrina milenarista y ese dato fundamental de la revelación cristiana que es la resurrección de los cuerpos: en perfecta consonancia con el doctor asiático, distingue los datos bíblicos que pueden hacer pensar a un abandono radical de la dimensión corpórea, refiriéndolos a la transformación final, mientras que el milenio es utilizado en función de valorizar también el aspecto material y corpóreo de la salvación cristiana. Se dirá que aquí, como un poco en todos los autores vistos, se configura una especie de dualismo escatológico. Yo personalmente desconfío del término dualismo aplicado a autores cristianos, y prefiero hablar más bien de una dualidad, dualidad que por cierto los autores encuentran en los textos bíblicos que se esfuerzan por interpretar fielmente.

Pasemos ahora al fundamental aporte de los Occidentales. Antes de Agustín, el milenarismo occidental no tiene características peculiares. En general notamos que 
se trata de una doctrina ampliamente difundida: lo atestiguan autores importantes como Tertuliano, Victorino de Petovio, el poeta Commodiano, Lactancio. Hasta bien entrado el siglo IV, el milenarismo occidental permanece todavía casi del todo inmunizado de la interpretación alegórica. Jerónimo aprenderá de Orígenes y Eusebio tal "novedad" exegética, pero sin aportes originales. El verdadero vuelco vendría en cambio de Ticonio y finalmente de Agustín.

En las obras hasta 396, Agustín sigue la tradición occidental favorable al milenarismo, entendido como período escatológico intermedio, pero ya depurado de los aspectos más materialísticos. Leamos por ejemplo este pasaje de un Sermón pronunciado en ocasión de la octava de Pascua (años 393-395):

Sermo 259, 2: "Este día octavo representa la vida nueva en el fin del mundo; el séptimo, representa el futuro reposo de los santos en esta tierra (Apoc 20, 4). Efectivamente, reinará el Señor en la tierra con sus santos, como dicen las Escrituras, y tendrá aquí una iglesia a la que ningún inicuo entrará, separada y purificada de todo contagio de iniquidad (Apoc 21, 27).

En otro Sermón sobre la octava de Pascua, del mismo período, explica aún más claramente:

Sermo 260 C, 3-5 "Con el número ocho se significan las cosas que pertenecen al siglo futuro, donde todo persevera unido en una inmutable beatitud, y habrá perpetuamente una quietud vigilante y una acción infatigabiliter otiosa". En el séptimo día, "si bien incluido en el giro de los días del tiempo presente, también habrá descanso: es el descanso prometido a los santos también sobre esta tierra y consiste en la exención de toda tempestad mundana que los moleste, hasta que, después de sus obras buenas, descansen en su Dios".

Es evidente por lo tanto aquí -como en otras obras del mismo período- el esquema teológico milenarista, que trata, de manera parecida a lo que hemos visto en Metodio, de integrar aspectos distintos y aparentemente difíciles de compatibilizar, mediante la sucesión cronológica sugerida, aunque enigmáticamente, por el Apocalipsis. Se trata en definitiva de una interpretación literal, que no se ha liberado todavía del mencionado dualismo, o mejor dicho dualidad escatológica.

Poco antes del año 400, Agustín experimentó un cambio de opinión exegética al propósito. Es difícil precisar cuándo exactamente haya llegado a tener contacto con la obra exegética del donatista Ticonio, autor de un Liber regularum para interpretar la Escritura, y de un Comentario al Apocalipsis. Sin embargo, ya en algunas obras anteriores a las Confesiones, la interpretación que distinguía con tanta claridad el significado del séptimo día con el octavo, empieza a coexistir con una interpretación que o identifica el día sábado con el reposo definitivo, sin lugar a un tiempo intermedio, y deja de lado la imagen del día octavo, o, de estar mencionado el día octavo, su significado se sobrepone, identificándose con el del día séptimo. Ejemplo interesante de esta evolución es el De diversis quaestionibus octoginta tribus.

En las Confesiones finalmente (sobre todo en el libro XIII), la concepción anterior es definitivamente superada, y Agustín utiliza ya el símbolo del sábado como imagen unívoca para indicar el reposo definitivo del hombre en Dios y de Dios en el hombre, según sus palabras, que con una serie de expresiones muy sugerentes aplican a la dimensión del tiempo la communicatio idiomatum entre Dios y la creatura humana. Sin embargo, los versículos sobre el milenio en el Apocalipsis 
eran demasiado conocidos e importantes como para poderse dejar sin una explicación satisfactoria. En los años siguientes, continuó la reflexión de Agustín sobre el tema, hasta llegar a la reflexión más completa y orgánica en el De Civitate Dei, libro XX. La solución de Ticonio en su comentario al Apocalipsis, ciertamente inspiró a Agustín: los mil años del reino de los justos significarían todo el tiempo de la Iglesia, desde la primera venida de Cristo hasta la segunda y definitiva. Agustín se dio cuenta de la genialidad de tal interpretación, que marca un decisivo progreso teológico, porque tiene en cuenta un punto fundamental y dificilísimo de entender, de toda la teología del Nuevo Testamento en su conjunto: se trata del tema de la "escatología realizada", que se encuentra expresado claramente en algunas páginas del epistolario paulino, en algunos pasajes de los Sinópticos, pero sobre todo es profundizado precisamente en el Corpus joánico. Esta concepción es prácticamente imposible de expresar en forma lógico-discursiva, y por lo tanto necesita de las fuertes imágenes del IV Evangelio y sobre todo del Apocalipsis. Esta concepción profundiza en el corazón mismo del misterio de Cristo, llegando a intuir que la realización de las profecías mesiánicas, y en definitiva la realización de toda esperanza del hombre y de toda creatura, ya se realiza, ya está realizada perfectamente en Cristo, si es que el creyente logra abrazar en una misma mirada, ya desenganchada de la lógica discursivo-temporal, tanto la Encarnación como la Redención realizada por el Dios Unigénito, Hijo del Hombre (5). Ya está realizada, sí, y sin embargo todavía espera su realización. Está en paz porque está realizada, y a la vez en tensión porque espera su realización. Esta intuición básica -aparentemente incoherente para nuestra lógica- está detrás de las enigmáticas imágenes del Apocalipsis, de la incoherencia cronológica de sus sorprendentes relatos y de sus números que desafían todo intento de descifración. En las últimas décadas, más de un exégeta del Apocalipsis (6), enfatizando la dimensión cristológica del libro, sin duda muy fuerte, ha incurrido en el error, más o menos pronunciado, de desvalorizar su dimensión escatológica. En mi opinión, no se deben en absoluto separar las dos dimensiones, cuya unidad el autor ha querido expresar. Diré más: la expresión de esta unidad fue el objetivo primario de su profecía. Aplicando el reino milenario al tiempo de la Iglesia, Ticonio justamente puso en evidencia esta enigmática tensión, característica esencial del concepto cristiano de Iglesia, entre la participación en la vida divina mediante la realidad de la redención ya operante, y la realidad del pecado que todavía está allí, encadenado pero no muerto. Se trata a la vez de un reino con Cristo, realidad perfecta, y sin embargo realidad que pasa, realidad temporal, que gime y sufre los dolores del parto. No podemos entrar aquí en todo el detalle de la profundización que Agustín hizo experimentar a la intuición básica de Ticonio. Si la eclesiología de Agustín logró profundizar mucho en los problemas planteados por los donatistas, no es menos cierto que también en el aspecto exegético el Hiponense logró sacar a luz coherentemente todas las consecuencias de esta interpretación del milenio, que no permite ya en absoluto una separación entre interpretación literal e interpretación alegórica, como en cierto modo había creído Orígenes. Se piensa normalmente que la interpretación de Agustín, aun siendo diferente de la interpreta-

(5) Ver por ejemplo Ev. Juan 3, 13.

(6) Uno de los más interesantes es sin duda el libro de Eugenio Corsini, Apocalisse prima e dopo. 
ción origeniana, es sin embargo también una interpretación alegórica, y tiene que ser catalogada por lo tanto en la misma categoría de la de Orígenes, y contrapuesta a la interpretación literal asiática. Yo creo que no es así. La interpretación del reino milenario como tiempo de la Iglesia es ciertamente simbólica con referencia al tenor literal del relato apocalíptico, y sin embargo recupera toda una dimensión material, justamente típica del milenarismo asiático de tradición judeo-cristiana. No solo en la referencia a la resurrección de los cuerpos, aspecto fundamental que ya habíamos visto en Metodio y que recibe en el De civitate Dei, libro XXII, su más amplio y coherente desarrollo, sino que la recupera, también, en todos los aspectos precisamente materiales que tienen relación con la Iglesia visible-invisible. Es cierto, sí, que "los justos" representan en rigor la Iglesia invisible, el conjunto de los santos. Sin embargo, Agustín sabe bien que la Iglesia visible, justamente por ser una realidad permixta, no es realmente separable de la Iglesia invisible, sino que guarda con ella una relación intrínseca, misteriosa pero real. El gesto visible que administra un sacramento, ya sea el bautismo o la unción de los enfermos, es un acto de dominio, de reino, que influye también en el mundo material, santificando el alma pero también el cuerpo; la intercesión de los santos, el simple contacto con una reliquia o la inmersión en el río Jordán sanan enfermedades muy materiales, y una orden de Jesús cambia el agua en vino, no alegóricamente. Sobre todos estos aspectos, que Agustín toca rápida o implícitamente, reflexionarán después los comentadores medievales, desde Cesario de Arles hasta Santo Tomás, mostrando toda la fecundidad de la intuición de Ticonio y Agustín.

El Milenio, justamente recogiendo importantes sugerencias agustinianas, llegará por lo tanto en la Edad Media a incluir cada vez más claramente, en esta dialéctica Iglesia visible-invisible, no solamente el tiempo de la Iglesia, sino todo el tiempo de la Historia.

Concluyendo: en Jesús, centro y recapitulación de la historia, habita corporalmente toda la plenitud de la divinidad. Esta habitación es de por sí invisible, sin embargo se manifiesta visiblemente, en las formas y momentos elegidos por Dios, en todas las dimensiones de la Creación. Pasados los "Mil años", Cristo dará el reino a su Padre, para que Dios sea finalmente Todo en todos. Donde el todos incluye justamente todas las dimensiones de la realidad, superando toda antinomía.

\section{RESUMEN}

El objetivo de este artículo es mostrar que las diferentes posturas exegéticas de los Padres sobre el Milenio del Apocalipsis, normalmente consideradas bajo el aspecto de la contraposición entre interpretación literal (más antigua, de origen judeo-cristiano y asiático) e interpretación alegórica (de influencia helénica y de ambiente alejandrino), pueden también ser vistas como complementarias, siendo que la primera rescata la dimensión más concreta, histórica y material tan importante en las promesas mesiánicas veterotestamentarias, mientras que la segunda subraya la necesidad de concebir los últimos tiempos como algo directamente más allá de las categorías empíricas espacio-temporales. En esta clave se considera el aporte del doctor donatista Ticonio y de San Agustín, que interpreta el Milenio como el tiempo histórico de la Iglesia, entre la primera y la segunda venida del Cristo, no como un nuevo tipo dentro de la interpretación alegórica, sino justamente como una reflexión que valora la complementación 
entre dimensión natural y sobrenatural, posible en la realidad eclesial gracias a la mediación cristológica. Esto se ve relacionado con el poderoso y complejo esfuerzo de reflexión antropológica y eclesiológica de Agustín, claves esenciales para entender su visión escatológica.

\begin{abstract}
This paper is intended to show that the different hexegetical theories of the Fathers about the Millennium in the Apocalypse, (which are normally considered as an opposition between an older, judeo-cristian, asiatic literal interpretation and a more recent, greek-influenced, alexandrian allegorical one) may also be seen as complementary. The first values the more concrete, historical and material aspect, so important in Old-Testament messianic promises, whereas the other shows the value of conceiving the "last times" as directly beyond the empirical space-time categories. In this light, the contribution of the donatist Tyconius and of St. Augustine, who interpret the Millennium as the historical time of the Church, between the first and second coming of the Lord, is no longer seen as a new type among other allegorical interpretations, but precisely as a thinking that values mutual complementing of the natural and supernatural dimension, made possible in the Church by the cristological intermediation. This is seen in connection to the powerful and complex effort of Augustine's anthropological and ecclesiological thinking, which are the clues to understand his eschatological perspective.
\end{abstract}

